\title{
Morfoanatomia e ontogênese do fruto e semente de Styrax camporum Pohl. (Styracaceae), espécie de cerrado do Estado de São Paulo ${ }^{1}$
}

\author{
PRICILA GREYSE DOS SANTOS JULIO² e DENISE MARIA TROMBERT OLIVEIRA ${ }^{2,3,4}$
}

(recebido: 23 de março de 2006; aceito: 22 de fevereiro de 2007)

\begin{abstract}
Morphology, anatomy and ontogeny of the fruit and seed of Styrax camporum Pohl. (Styracaceae), a "cerrado" species of the São Paulo State). We studied the fruits and seeds of Styrax camporum Pohl. (Styracaceae), a typical tree of the Brazilian "cerrado", aiming to describe their morphology, anatomy, and ontogeny. Samples of fruits and seeds were collected and processed by standard techniques. Developing fruits were classified into four stages: I - initial stage, characterized by ovaries of the floral bud; II - ovary of the flower in post-anthesis and young fruits; III - pre-mature fruits; IV - mature fruits. The fruit is fleshy and monospermic, with a persistent calyx. The pericarp presents a uniseriate exocarp, with stellate lignified trichomes and dome-shaped cells of irregular sizes. The outer mesocarp consists of multisseriate parenchyma, radially elongated at maturity. Vascular bundles are observed in the inner third part of the mesocarp. In spite of the fruit of this species to be classified as a drupe, its inner mesocarp and endocarp are composed by a few fiber layers only, without forming the pyrene with the typical hardness of these kind of fruit. The endocarp fusion with the seed coat is not seen. The seed is typical of the Styracaceae; it is unitegmic, with multiseriate and thick testa. The exotesta is uniseriate and some layers of stone cells are seen in the outer mesotesta. Internally to these cells, some vascular bundles occur, followed by many layers of parenchyma cells, containing evident lipid reserve. The embryo is axial, straight and espatulate, consisting of a typical embryonic axis and leaflike cotyledons.
\end{abstract}

Key words - anatomy, fruit, morphology, seed, Styrax camporum

RESUMO - (Morfoanatomia e ontogênese do fruto e semente de Styrax camporum Pohl. (Styracaceae), espécie de cerrado do Estado de São Paulo). Foram estudados os frutos e sementes de Styrax camporum Pohl. (Styracaceae), espécie arbórea típica dos cerrados brasileiros, objetivando descrever sua morfologia, anatomia e ontogênese. Amostras de frutos e sementes foram coletadas e processadas pelas técnicas convencionais. Os frutos em desenvolvimento foram enquadrados em quatro estádios: I - estádio inicial, caracterizado pelos ovários dos botões florais; II - ovário de flor pós-antese e frutos jovens; III frutos pré-maturação; IV - frutos maduros. Verificou-se que o fruto é carnoso e monospérmico, com cálice persistente. $\mathrm{O}$ pericarpo apresenta exocarpo unisseriado, com tricomas estrelados lignificados e células de formato abaulado e tamanhos irregulares. O mesocarpo externo se constitui de tecido parenquimático multisseriado, alongado radialmente na maturidade. Feixes vasculares estão presentes no terço interno do mesocarpo. Apesar do fruto desta espécie ser classificado como drupa, observou-se que o mesocarpo interno e o endocarpo são compostos apenas por poucas camadas de fibras, não formando o pirênio com a dureza típica desse tipo de fruto; também não se observa o concrescimento do endocarpo com o tegumento. A semente é típica da família Styracaceae, ou seja, é unitegumentada, apresentando testa multisseriada e bastante espessa, sendo a exotesta unisseriada. Na mesotesta externa, verificam-se várias camadas de braquiesclereídes. Internamente a essas células, ocorrem diversos feixes vasculares, seguidos por numerosas camadas de células parenquimáticas, que contêm evidente reserva de substâncias lipídicas. O embrião é axial, reto e espatulado, constituído pelo eixo embrionário típico e cotilédones foliáceos.

Palavras-chave - anatomia, fruto, morfologia, semente, Styrax camporum

1. Parte da dissertação de mestrado do primeiro autor, Programa de Pós-graduação em Ciências Biológicas (Botânica), Instituto de Biociências, Universidade Estadual Paulista, UNESP, Botucatu, SP, Brasil.

2. UNESP - Universidade Estadual Paulista, Instituto de Biociências, Departamento de Botânica, Caixa Postal 510, 18618-000 Botucatu, SP, Brasil.

3. Endereço atual: Universidade Federal de Minas Gerais, Instituto de Ciências Biológicas, Departamento de Botânica, Avenida Antonio Carlos, 6627, Pampulha, Caixa Postal 486, 31270-901 Belo Horizonte, MG, Brasil.

4 .

\section{Introdução}

Segundo a análise filogenética realizada por Judd et al. (1999), a família Styracacae está incluída na Ordem Ericales. As Styracaceae são plantas arbustivas ou arbóreas, abrangendo cerca de 11 gêneros e 150 espécies (Dickison 1993). Segundo Mendonça et al. (1998), nos cerrados ocorrem nove espécies da família, distribuídas em matas secas, matas de galeria e cerrado senso estrito. 
O gênero Styrax L. possui cerca de 120 espécies distribuídas nas regiões tropicais e subtropicais, como no Sudeste da Ásia, Oeste da Malásia e Américas (Hutchinson 1973, Nakajima \& Monteiro 1986, Dickison 1993). No Brasil, são encontradas cerca de 25 espécies deste gênero (Nakajima \& Monteiro 1986), sendo que três estão presentes nos cerrados brasileiros: Styrax camporum Pohl., S. ferrugineus Nees et Mart. e $S$. martii Seub. (Nakajima \& Monteiro 1986, Saraiva et al.1988). São árvores que podem atingir de 6 a $14 \mathrm{~m}$ de altura, com tronco de 30 a $40 \mathrm{~cm}$ de diâmetro, apresentando folhas simples, alternas, pecioladas, coriáceas, com tricomas estrelados (Perkins 1907, Lorenzi 1992).

Styrax camporum é conhecida popularmente por estoraque-do-campo (Mors \& Rizzini 1966), benjoeiro, cuia-do-brejo, canela-poca, fruta-de-pomba, pinduíba (Lorenzi 1992) e laranjeirinha (Rodrigues \& Carvalho 2001). Ocorre nos Estados de Minas Gerais, São Paulo, Mato Grosso do Sul e Paraná, sendo indicada para reflorestamentos destinados à recomposição de áreas degradadas. A espécie produz grande quantidade de sementes viáveis retidas em frutos carnosos, os quais são dispersados por aves (Lorenzi 1992).

Considerando a freqüência das espécies de Styrax nos cerrados de São Paulo, bem como a carência de dados morfoanatômicos sobre seus órgãos reprodutivos, realizou-se um estudo com frutos e sementes de $S$. camporum, objetivando caracterizar sua morfologia, anatomia e ontogênese.

\section{Material e métodos}

O material de Styrax camporum Pohl. constou de botões florais, flores em pré-antese, antese e pós-antese, frutos jovens, maduros e respectivas sementes, e foi coletado em áreas de cerrado da Fazenda Palmeira da Serra, em Pratânia, SP, Brasil, e nos arredores do Município de Botucatu, SP. As características morfológicas dos frutos e sementes foram descritas e ilustradas a partir de amostras provenientes de ao menos cinco indivíduos. Parte do material coletado foi herborizado e depositado no Herbário "Irina Delanova de Gemtchujnicov" (BOTU), do Departamento de Botânica, Instituto de Biociências da UNESP, Câmpus de Botucatu, como documento taxonômico, registrado sob o número 23.894.

Para o estudo anatômico, as amostras foram fixadas em FAA em etanol 50\% (Johansen 1940) ou em solução de Karnovsky (Karnovsky 1965), sendo conservadas em etanol a 70\%.

Para o laminário permanente, as amostras foram desidratadas em série etílica, infiltradas e incluídas em metacrilato (Gerlach 1969), seccionadas em micrótomo, coradas em azul de toluidina a $0,05 \%$ (O'Brien et al. 1964) e montadas em resina sintética.

Foi realizada a maceração do pericarpo e tegumento maduros, de acordo com a técnica de Franklin, modificada conforme sugerido por Kraus \& Arduin (1997).

Secções de material fresco, obtidas em micrótomo manual, foram submetidas a corantes e/ou reagentes específicos, como: vermelho de rutênio, para identificar polissacarídeos diversos e pectinas (Johansen 1940); floroglucinol acrescido de ácido clorídrico, para evidenciar paredes lignificadas (Sass 1951); Sudan IV, para a localização de substâncias lipídicas; lugol, para a detecção de amido; cloreto férrico, acrescido de carbonato de sódio, para verificar a ocorrência de compostos fenólicos (Johansen 1940).

Para caracterização da micromorfologia de superfície, as amostras foram processadas segundo a técnica descrita por Robards (1978). As amostras foram analisadas e fotografadas com filme Technical Pan asa 25 em microscópio eletrônico de varredura (MEV) Phillips SEM-515.

Para ilustração de caracteres gerais, desenhos foram elaborados em estereomicroscópio Zeiss com câmara clara acoplada. Fotomicrografias foram produzidas através de fotomicroscópio Zeiss, modelo MC80. Para todas as ilustrações, foram preparadas escalas nas condições ópticas adequadas.

\section{Resultados}

Estádio I (figuras 1-9) - Em S. camporum, a fase inicial do desenvolvimento dos frutos refere-se ao ovário de botões florais e flores em antese, o qual é súpero (figura 1), tricarpelar e de placentação axial (figuras 1-2). Na região basal, identifica-se a formação de curto hipanto, distinguindo-se numerosos traços vasculares, além da vascularização típica do ovário (figura 2). Na região onde os óvulos estão implantados, o ovário é trilocular (figura 2) e, à medida que se aproxima do ápice, observa-se que os septos são separados na região central, formando um único lóculo (figura 3), como resultado da fusão carpelar incompleta nesta espécie.

A epiderme externa é composta por células de parede delgada de formato irregular, vacuoladas (figura 4), de conteúdo fenólico e com núcleo evidente. Ocorrem numerosos tricomas estrelados pedunculados ou sésseis, lignificados, de parede espessa, compostos por sete ou mais células (figura 5). Em função do aumento de espessura das paredes, o lume das células destes tricomas fica bastante reduzido (figura 5). 

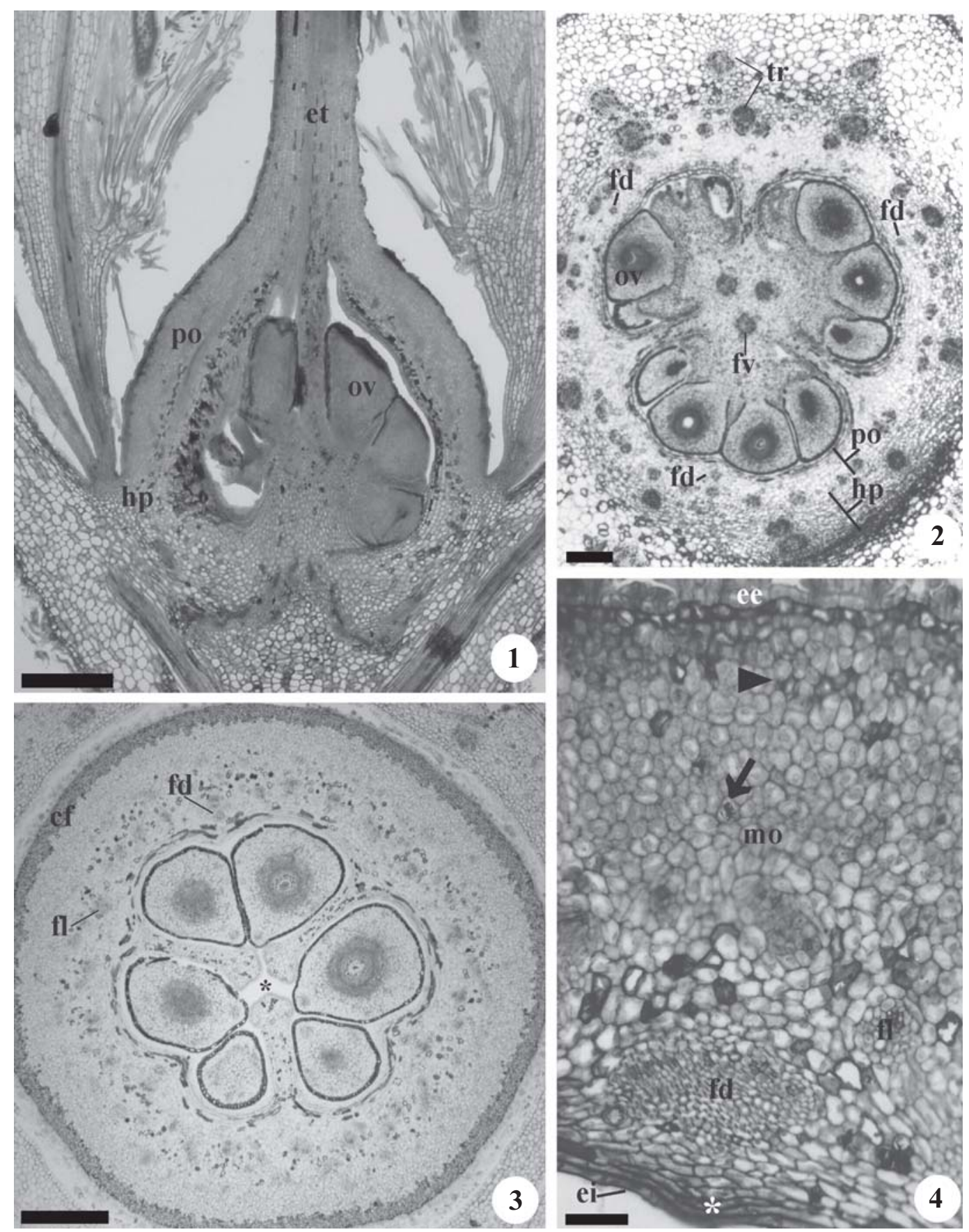

Figuras 1-4. Styrax camporum Pohl. Estádio I. Ovário do botão floral. Secções longitudinais (1) e transversais (2-4). 1. Aspecto geral do ovário. 2. Região basal do ovário, evidenciando três lóculos isolados. 3. Região apical do ovário; notar os septos separados na região central $(*)$. 4. Detalhe da parede ovariana; notar células alongadas nas camadas internas do mesofilo (*). ( $\mathrm{seta}=$ cristal; ponta de seta $=$ idioblasto fenólico; $\mathrm{cf}=$ célula fenólica; ee $=$ epiderme externa; ei $=$ epiderme interna; et $=$ estilete; $\mathrm{fd}=$ feixe dorsal; $\mathrm{fl}=$ feixe lateral; $\mathrm{fv}=$ feixe ventral; $\mathrm{hp}=$ hipanto; $\mathrm{mo}=$ mesofilo ovariano; ov = óvulo; $\mathrm{po}=$ parede ovariana; $\operatorname{tr}=$ traço). Barras $=1 \mathrm{~mm}(1), 500 \mu \mathrm{m}(3), 200 \mu \mathrm{m}(3), 50 \mu \mathrm{m}(4)$.

Figures 1-4. Styrax camporum Pohl. Stage I. Ovary of the floral bud. Longitudinal section (1) and transverse sections (2-4). 1. General aspect of the ovary. 2. Basal region of the ovary, showing three isolated locules. 3. Apical region of the ovary; to note the separated septa in central region $(*)$. 4. Detail of the ovarian wall; to note elongated cells in the inner layers of the mesophyll $(*)$. $($ arrow $=$ crystal; arrowhead $=$ phenolic idioblast; $\mathrm{ee}=$ outer epidermis; $\mathrm{ei}=$ inner epidermis; et $=$ style; $\mathrm{fd}=\mathrm{dorsal}$ bundle; $\mathrm{fl}=$ lateral bundle; $\mathrm{fv}=$ ventral bundle; $\mathrm{hp}=$ hypanthium; $\mathrm{mo}=$ ovarian mesophyll; ov = ovule; $\mathrm{po}=\mathrm{ovarian}$ wall; $\mathrm{tr}=\operatorname{trace}$ ). Bars $=1 \mathrm{~mm}(1), 500 \mu \mathrm{m}(3), 200 \mu \mathrm{m}(3), 50 \mu \mathrm{m}(4)$. 
No mesofilo ovariano, algumas células mais externas apresentam conteúdo fenólico (figuras 3-4), sendo seguidas por várias outras camadas de células parenquimáticas, de diversos formatos e tamanhos (figura 4). Dispersos neste parênquima, encontram-se numerosos idioblastos cristalíferos contendo drusas e também idioblastos fenólicos (figura 4). Duas a três camadas mais internas do mesofilo apresentam-se alongadas tangencialmente à epiderme interna (figuras $4,7)$.

Na porção do ovário não adnata ao hipanto, imersos no terço interno do mesofilo, ocorrem três feixes dorsais e três ventrais, do tipo colateral, além de vários cordões procambiais laterais (figura 2). Os feixes ventrais vascularizam os óvulos (figura 7) na região proximal do ovário e não se continuam na região próxima ao estilete (figura 3,6), onde permanecem apenas os dorsais e os laterais.

A epiderme interna do ovário possui uma camada de células de parede delgada, ligeiramente alongadas horizontalmente (figura 4), as quais tornam-se papilosas na região de placentação e estendem-se até as extremidades isoladas dos septos, na porção unilocular do ovário (figura 6).

Os óvulos são anátropos e bitegumentados, com os dois tegumentos mais evidentes na região da micrópila (figura 8). No tegumento externo, a epiderme externa é composta por células fenólicas (figuras 2-3, 6-9) e o mesofilo possui cerca de sete camadas de células de natureza fundamental, sendo as mais internas de conteúdo mais denso e indistintas da epiderme interna. Na rafe, observa-se o único feixe vascular do óvulo (figuras 7,9). O tegumento interno apresenta em torno de quatro camadas. São células alongadas horizontalmente, possuindo citoplasma denso (figura 8). A camada mais interna do tegumento interno constitui o endotélio, o qual possui células alongadas radialmente (figuras 8-9). Na região central do óvulo, observa-se uma camada de nucelo (figura 8 ), sob a qual se diferencia o megasporocito, caracterizando a estrutura tenuinucelada.

Estádio II (figuras 10-15) - Início do desenvolvimento do fruto e semente, representado pelo ovário da flor pós-antese e fruto jovem, acompanhado pelo cálice persistente.

Nesta fase, o pericarpo mantém-se muito semelhante à parede ovariana (figuras 10-11), aumentando ligeiramente sua espessura pela ocorrência de divisões celulares aleatórias, em sentidos variáveis, no mesofilo. Os feixes laterais diferenciam-se em estruturas colaterais.
O único óvulo fecundado inicia sua maturação como semente, distinguindo-se dos demais pelo grande crescimento, resultante de numerosas divisões periclinais na mesotesta e anticlinais em todas as regiões (figura 12). Tais divisões permitem o crescimento da semente que, neste estádio, é ainda muito jovem, porém já assume mais que o dobro do tamanho dos óvulos não fecundados; estes são abortados e degeneram, apresentando aspectos variados nesta fase (figuras 10-12).

Ao mesmo tempo em que a semente jovem rapidamente preenche a região dos lóculos, os septos vão sendo comprimidos, assumindo, no fruto jovem a condição unilocular.

O aumento de tamanho que se observa nos frutos ao longo desta fase não é propriamente do pericarpo, que mantém a espessura praticamente inalterada, sofrendo apenas divisões anticlinais e raras periclinais, que permitem comportar o aumento do diâmetro da semente. A semente é que cresce consideravelmente. Comparando-se as secções transversais do ovário no Estádio I (figura 3) e o fruto jovem no Estádio II (figura $10)$, pode-se confirmar o relatado.

Ao final do Estádio II, não se verificam alterações exocárpicas. No mesocarpo externo, as células das quatro camadas subexocárpicas tornam-se colenquimatosas, seguindo-se de ampla região parenquimática (figura 14). Na parte mais interna desta região se encontram imersos vários feixes vasculares, que se apresentam próximos ao mesocarpo interno. Este exibe alongamento horizontal de suas células (figura 14), que começam a se lignificar. O endocarpo mantém-se unisseriado (figura 13), composto por células menores e mais densas que as adjacentes.

A semente agora preenche completamente o lóculo, tendo aumentado cerca de dez vezes o seu tamanho inicial (comparar as figuras 10 e 13).

A exotesta é unisseriada (figura 13) e ocorre a presença de compostos fenólicos em suas células. A mesotesta apresenta-se muito ampliada, com vários feixes vasculares, os quais constituem extensões póscalazais produzidas neste período, delimitando o quarto externo mesotestal (figura 13). A endotesta é indiferenciada.

No tégmen não há diferenciação entre camadas e as células vão se tornando colapsadas (figuras 13, $15)$.

O endosperma apresenta-se bem diferenciado e suas células periféricas apresentam células paredes delgadas; internamente à epiderme, ocorre um tecido 


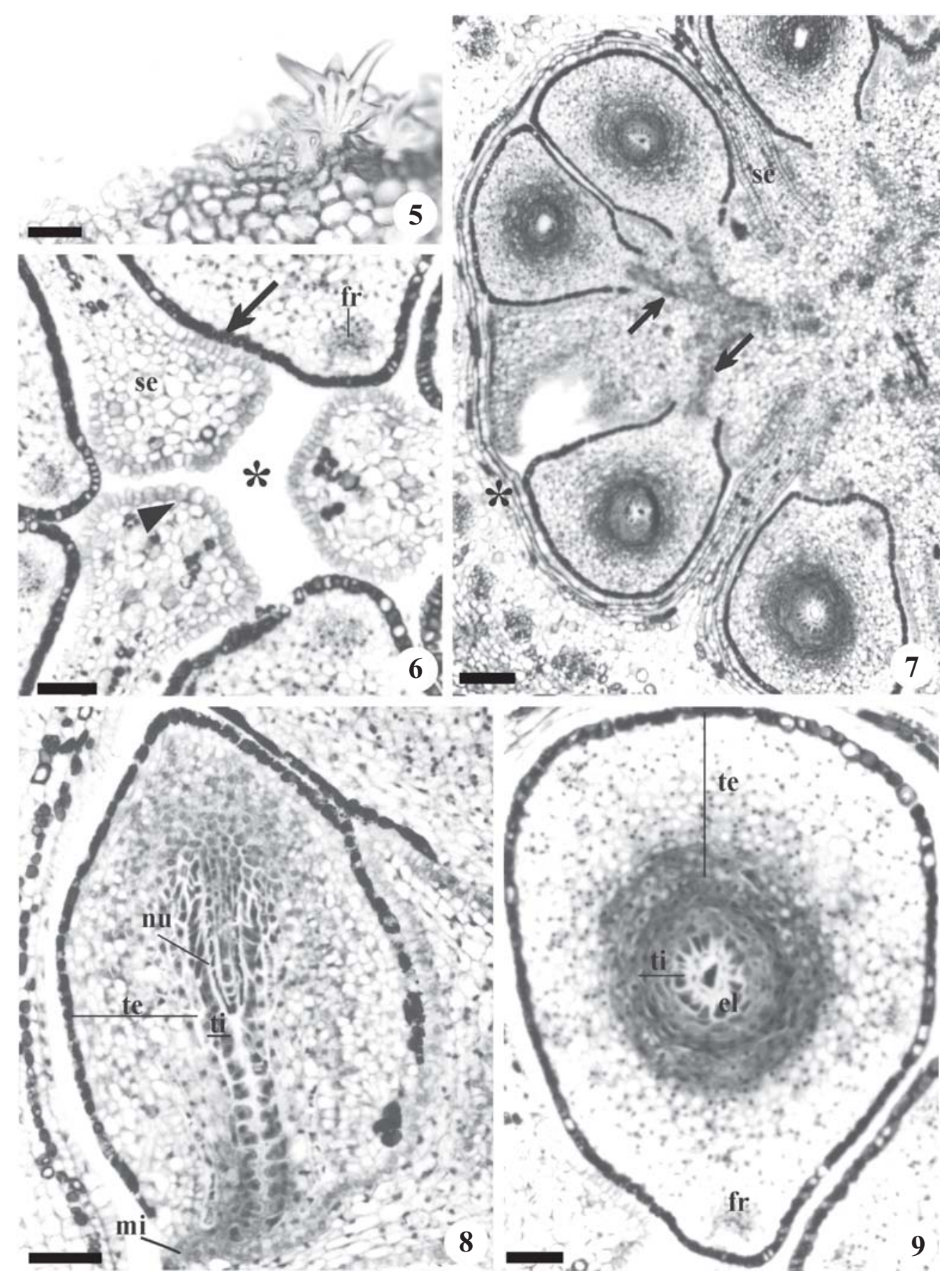

Figuras 5-9. Styrax camporum Pohl. Estádio I. Detalhes do ovário e óvulo. Secções longitudinal (8) e transversais (5-7, 9). 5. Epiderme externa evidenciando o tricoma estrelado. 6. Detalhe da região apical do ovário, com os septos separados (*); observar células papilosas (ponta de seta) e a epiderme fenólica dos óvulos (seta). 7. Região basal do ovário, evidenciando traços ventrais irrigando os óvulos (setas); notar o alongamento das células internas do mesofilo (*). 8-9. Aspecto geral do óvulo. $(\mathrm{el}=$ endotélio; $\mathrm{fr}=$ feixe rafeal; $\mathrm{mi}=$ micrópila; $\mathrm{nu}=$ nucelo; $\mathrm{se}=$ septo; te = tegumento externo; ti = tegumento interno $)$. Barras $=100 \mu \mathrm{m}(7), 50 \mu \mathrm{m}(5-6,8-9)$.

Figures 5-9. Styrax camporum Pohl. Stage I. Details of the ovary and ovule. Longitudinal section (8) and transverse sections $(5-7,9)$. 5. Outer epidermis, showing stellate trichome. 6. Detail of the apical region of the ovary, with separated septa $(*)$; to observe papillose cells (arrowhead) and the phenolic epidermis of ovules (arrow). 7. Basal region of the ovary, evidencing ventral traces that irrigate the ovules (arrows); note the elongation of the inner cells of the mesophyll (*). 8-9. General aspect of the ovule. $(\mathrm{el}=$ endothelium; $\mathrm{fr}=$ rapheal bundle; $\mathrm{mi}=$ micropyle; $\mathrm{nu}=$ nucellus; $\mathrm{se}=$ septum; te = outer integument; $\mathrm{t}=\mathrm{inner}$ integument). Bars $=100 \mu \mathrm{m}(7), 50 \mu \mathrm{m}(5-6,8-9)$. 


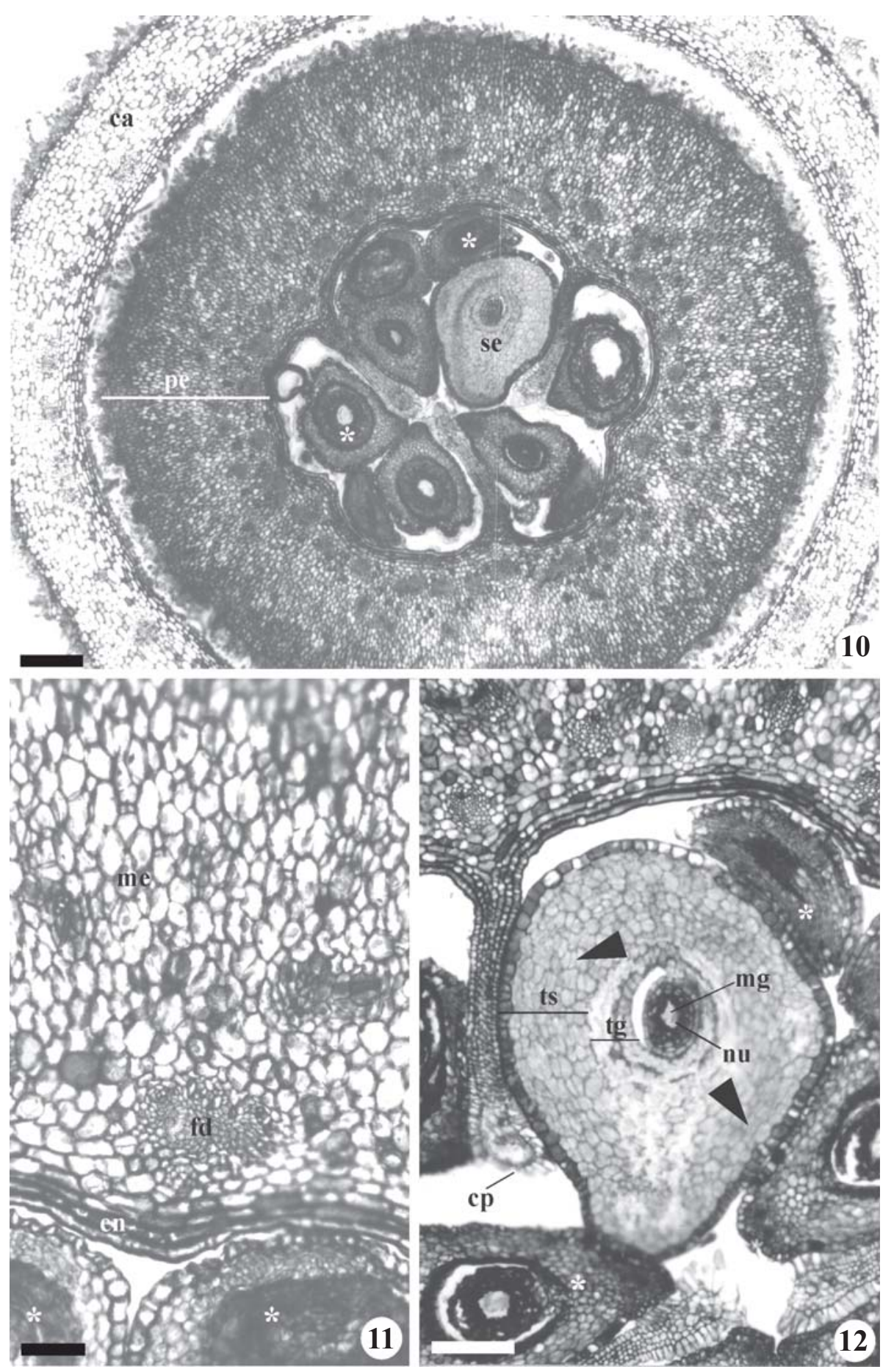

Figuras 10-12. Styrax camporum Pohl. Estádio II. Secções transversais de ovário pós-antese. 10. Aspecto geral; notar a presença do cálice. 11. Detalhe do mesocarpo e endocarpo. 12. Detalhe da figura 10, mostrando as células papilosas do endocarpo e a maior separação dos septos, produzida pelo crescimento do único óvulo fecundado (ponta de seta = divisões periclinais). (ca = cálice; $\mathrm{cp}=$ células papilosas; $\mathrm{en}=$ endocarpo; $\mathrm{fd}=$ feixe dorsal; $\mathrm{me}=$ mesocarpo; $\mathrm{mg}=$ megagametofito; $\mathrm{nu}=$ nucelo; $\mathrm{pe}=$ pericarpo; $\mathrm{se}$ $=$ semente; $\operatorname{tg}=$ tégmen; ts $=$ testa; ${ }^{*}=$ óvulos abortados). Barras $=200 \mu \mathrm{m}(10), 100 \mu \mathrm{m}(12), 50 \mu \mathrm{m}(11)$.

Figures 10-12. Styrax camporum Pohl. Stage II. Transverse sections of the post-anthesis ovary. 10. General aspect; note the presence of the calyx. 11. Detail of mesocarp and endocarp. 12. Detail of figure 10, showing the papillose cells of endocarp and the bigger separation of the septa, produced by the growth of only fecundated ovule (arrowhead = periclinal division). (ca = calyx; $\mathrm{cp}=$ papillose cells; $\mathrm{en}=$ endocarp; $\mathrm{fd}=$ dorsal bundle; $\mathrm{me}=$ mesocarp; $\mathrm{mg}=$ megagametophyte; $\mathrm{nu}=$ nucellus; $\mathrm{pe}=$ pericarp; se $=$ seed; $\operatorname{tg}=$ tegmen; ts $=$ testa; $*=$ aborted ovules). Bars $=200 \mu \mathrm{m}(10), 100 \mu \mathrm{m}(12), 50 \mu \mathrm{m}(11)$. 
de células com formatos irregulares, núcleos evidentes e bastante vacuoladas (figura 15). Neste estádio, o embrião ainda está no início de sua formação, ocupando pequeno volume da semente; nele podem ser reconhecidos o suspensor, voltado para a região micropilar, e o embrião propriamente dito.

Estádio III (figuras 16-41) - Fase caracterizada pela maturação da semente (figuras 17-20). Os frutos em estádios avançados do desenvolvimento (figura 16) possuem coloração verde-clara e seu indumento ainda visível.

No exocarpo, as células epidérmicas comuns apresentam parede delgada e formato abaulado e irregular (figuras 21-22, 24, 26). Os tricomas observados são idênticos aos da estrutura inicial, sendo estrelados, lignificados e sésseis ou pedunculados (figura 24). As células que os constituem exibem paredes espessas, com a extremidade distal afilada gradualmente e a proximal apresentando uma projeção (figura 25), que se insere entre as demais células exocárpicas.

O mesocarpo externo está representado por camadas de células colenquimatosas periféricas, ligeiramente espessadas (figuras 21-22), internamente às quais ocorre um tecido parenquimático composto por células cujos formatos variam de irregular a isodiamétrico (figuras 21-22, 26-27). O mesocarpo interno apresenta células alongadas e lignificadas, constituindo fibras de diversos tamanhos, dispostas horizontalmente em cerca de três camadas, seguidas pelo endocarpo unisseriado, de características similares (figuras 21, 23, 26-27).

Dispersos por todo o mesocarpo externo, observam-se idioblastos cristalíferos e fenólicos. $\mathrm{Na}$ região interna do mesocarpo externo, podem-se verificar vários feixes vasculares colaterais (figuras 21, 23).

As sementes são anátropas, marromalaranjadas e de formato elíptico, apresentando uma reentrância assimétrica na região hilo-micropilar, que caracteriza o lobo radicular (figura 17). A rafe é visível externamente como ligeiro sulco, assim como também se destacam algumas extensões póscalazais (figuras 17-19). O hilo é amplo e de contorno irregular, ficando a micróplia sobre o lobo radicular (figura 18).

A exotesta não se modifica (figuras 28-30), apenas acumula compostos fenólicos. Na mesotesta, a camada externa aos feixes vasculares apresenta gradual espessamento das paredes celulares (figuras
28-30), que se tornam lignificadas, constituindo braquiesclereídes (figura 32). Tais células exibem contornos variáveis, sendo muitas vezes isodiamétricas; suas paredes apresentam grande espessamento e aspecto lamelado, abrigando numerosas pontoações simples (figura 32). No limite interno desta camada de esclereídes, os feixes vasculares rafeal (figura 28) e que constituem as extensões pós-calazais (figura 30) mostram-se anficrivais (figura 28). A mesotesta interna é composta por células parenquimáticas de tamanhos variáveis, tendendo a isodiamétricas (figuras 28, 30), que, na maturidade, acumulam grande quantidade de substâncias lipídicas.

O tégmen foi reabsorvido, mantendo-se apenas resíduos de suas paredes celulares, visíveis como um depósito de natureza péctica entre a testa e o endosperma (figuras 30-31, 33,37).

No início deste estádio, o endosperma (figura 31), permanece com as mesmas características descritas na fase anterior (figura 15). Ao final, contudo, os citoplasmas das células do endosperma tornam-se mais densos (figura 35), armazenando substâncias lipídicas. Embora persistente na semente adulta, o endosperma ocupa menor volume, em função do crescimento e diferenciação do embrião. O endosperma é restrito junto à base do embrião (figuras 33,37), sendo mais abundante ao redor dos cotilédones (figura 35 ).

Ao final do Estádio III, o embrião já está formado (figura 20), ainda conectado ao suspensor. Ele apresenta eixo hipocótilo-radícula reto, cilíndrico (figura 33), plúmula indiferenciada (figura 34), localizando-se na região axial da semente (figuras 35-36); seus cotilédones são foliáceos, encontrando-se justapostos (figura 34). A protoderme do eixo embrionário é composta por células cubóides de parede delgada (figuras 34, 37). O procâmbio ocupa a disposição típica de cada região, imerso no meristema fundamental (figuras 33-34, 36). No nó cotiledonar, é possível verificar os traços procambiais que promovem a irrigação dos cotilédones (figura 34). Neste estádio, ainda é possível reconhecer resquícios das células do suspensor, já em degeneração.

Os cotilédones são delgados e exibem estrutura simples, com a protoderme da face adaxial composta por células mais volumosas que a abaxial (figura 36). $\mathrm{O}$ mesofilo cotiledonar é composto por meristema fundamental, onde se inserem pequenos cordões procambiais. Na região da nervura mediana, ampliamse as camadas de meristema fundamental e a dimensão do cordão procambial central, produzindo discreta projeção em direção à face abaxial (figura 36 ). 

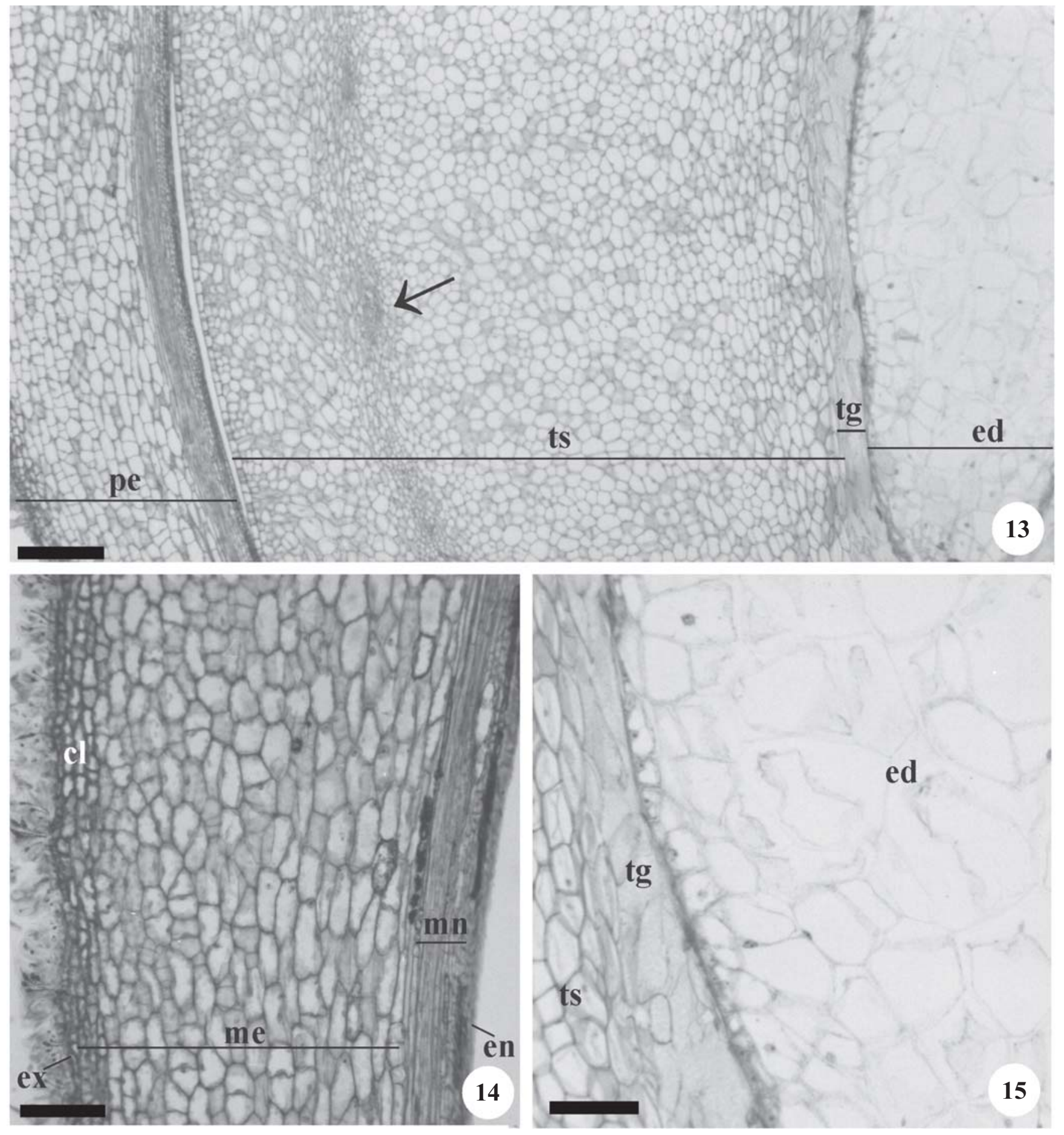

Figuras 13-15. Styrax camporum Pohl. Estádio II. Fruto jovem. Secções longitudinais $(13,15)$ e transversal (14). 13. Aspecto geral do pericarpo e semente $(\mathrm{seta}=$ feixe vascular). 14 . Detalhe do pericarpo. 15 . Detalhe da semente. $(\mathrm{cl}=\mathrm{colênquima;}$ ed $=$ endosperma; en $=$ endocarpo; $\mathrm{ex}=$ exocarpo; $\mathrm{me}=$ mesocarpo externo; $\mathrm{mn}=$ mesocarpo interno; $\mathrm{pe}=$ pericarpo; $\operatorname{tg}=$ tégmen; ts $=$ testa). Barras $=200 \mu \mathrm{m}(13), 100 \mu \mathrm{m}(14-15)$.

Figures 13-15. Styrax camporum Pohl. Stage II. Young fruit. Longitudinal sections $(13,15)$ and transverse section (14). 13. General aspect of the pericarp and seed (arrow $=$ vascular bundle). 14. Detail of the pericarp. 15 . Detail of the seed. $(\mathrm{cl}=$ collenchyma; ed = endosperm; en = endocarp; ex = exocarp; $m e=$ outer mesocarp; $\mathrm{mn}=$ inner mesocarp; $\mathrm{pe}=$ pericarp; $\operatorname{tg}=$ tegmen; ts = testa). Bars $=200 \mu \mathrm{m}(13), 100 \mu \mathrm{m}(14-15)$. 

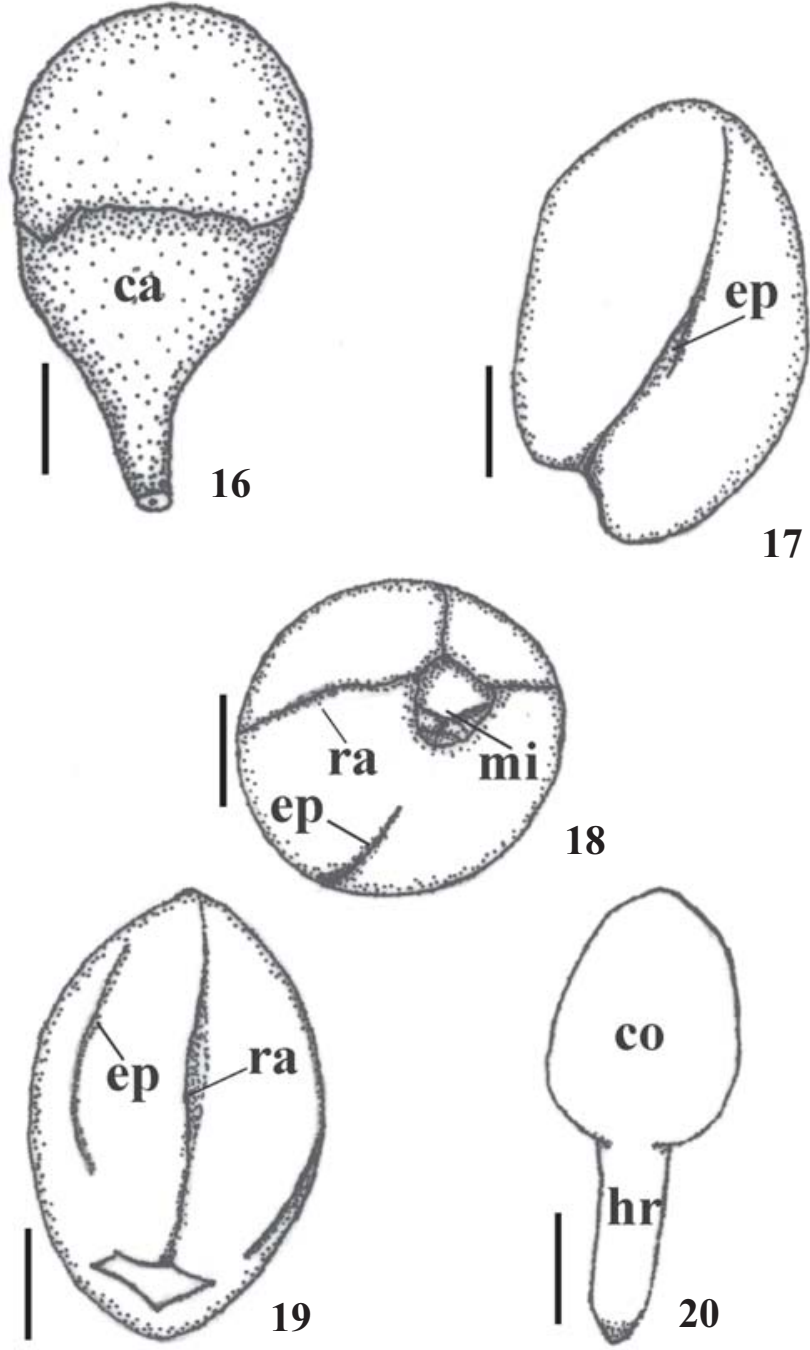

19
18

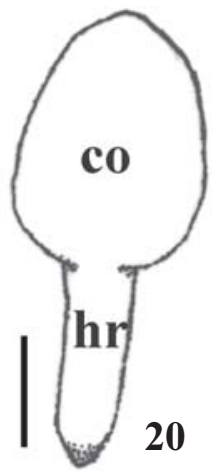

Figuras 16-20. Styrax camporum Pohl. Estádio III. Fruto e semente. Aspectos gerais do fruto imaturo (16) e de sementes (17-19). 17. Vista lateral. 18. Vista hilo-micropilar. 19. Vista láterorafeal. 20. Embrião. $(c a=$ cálice; $c o=$ cotilédone; ep = extensão pós -calazal; $\mathrm{hr}=$ eixo hipocótilo-radícula; $\mathrm{mi}=$ micrópila; $\mathrm{ra}=$ rafe). Barras $=2 \mathrm{~mm}(16-19), 1 \mathrm{~mm}(20)$.

Figures 16-20. Styrax camporum Pohl. Stage III. Fruit and seed. General aspects of the immature fruit (16) and seed (17-19) 17. Lateral view. 18. Hilum-micropylar view. 19. Lateral-rapheal view. 20. Embryo. (ca = calyx; co = cotyledon; $\mathrm{ep}=$ post-chalazal extension; $\mathrm{hr}=$ embryo axis; $\mathrm{mi}=$ micropyle; $\mathrm{ra}=$ raphe). Bars $=2 \mathrm{~mm}$ (16-19), $1 \mathrm{~mm}$ (20).

Estádio IV (figuras 38-43) - O fruto maduro tem cálice persistente, formato arredondado e coloração verde escuro-arroxeada. Sua consistência é carnosa, formando um pirênio de lóculo único que contém uma só semente.

A estrutura do fruto maduro é bastante semelhante ao fruto jovem, não se registrando alterações no exocarpo, a não ser a redução da densidade de tricomas (figura 38), em função do alongamento tangencial das células comuns.

A maior alteração observada durante o amadurecimento do pericarpo é o considerável aumento de espessura do mesocarpo externo, cujas células alongam-se no sentido radial, especialmente nas camadas mais periféricas (figura 38). Os vários feixes vasculares do mesocarpo externo não se modificam (figura 39).

O mesocarpo interno e endocarpo também mantêm as características da fase anterior (figuras 38-41), exibindo, porém, lignificação mais intensa. Observa-se que as fibras são levemente encurvadas, com as extremidades afiladas (figuras 42-43), arredondadas ou irregulares. Quando o fruto é despolpado manualmente, pode-se notar a consistência papirácea do mesocarpo interno associado ao endocarpo.

Na semente, única mudança que ocorre nesta fase é que a exotesta torna-se colapsada entre o endocarpo e a mesotesta lignificados, o que produz deformação de suas células. No endosperma e no embrião, não foram constatadas mudanças.

\section{Discussão}

Em S. camporum Pohl., verificou-se que o ovário é trilocular na base e unilocular no ápice. A partir de observação similar, Aranha (1968) descreveu o ovário de Styrax como sendo pseudo-trilocular. Dickison (1993), em seu trabalho sobre anatomia floral de diversos gêneros da família Styracaceae, descreveu os ovários das espécies de Styrax, citando que os lóculos são incompletos na metade superior do ovário. $\mathrm{O}$ autor afirmou que esta característica ocorre na maioria dos táxons de Styracaceae.

Apesar de $S$. camporum ser descrita como portadora de ovário súpero, verificou-se, na região basal, adnação a um hipanto restrito. Dickison (1993) relatou que o gênero Styrax apresenta ovários que variam de súperos a ínferos. Considerando que a tendência evolutiva conduz à condição ínfera, a presença de ovário súpero com tão restrito hipanto ainda pode ser considerada uma etapa intermediária entre a condição súpera e ínfera.

A ocorrência de tricomas estrelados, característica freqüente na família, foi verificada por toda a epiderme externa do ovário, mantendo-se até o pericarpo maduro. Estes tricomas foram descritos anteriormente para as Styracaceae por diversos autores (Perkins 1907, Fahn 1986, Machado 1991, Dickison 1993). 

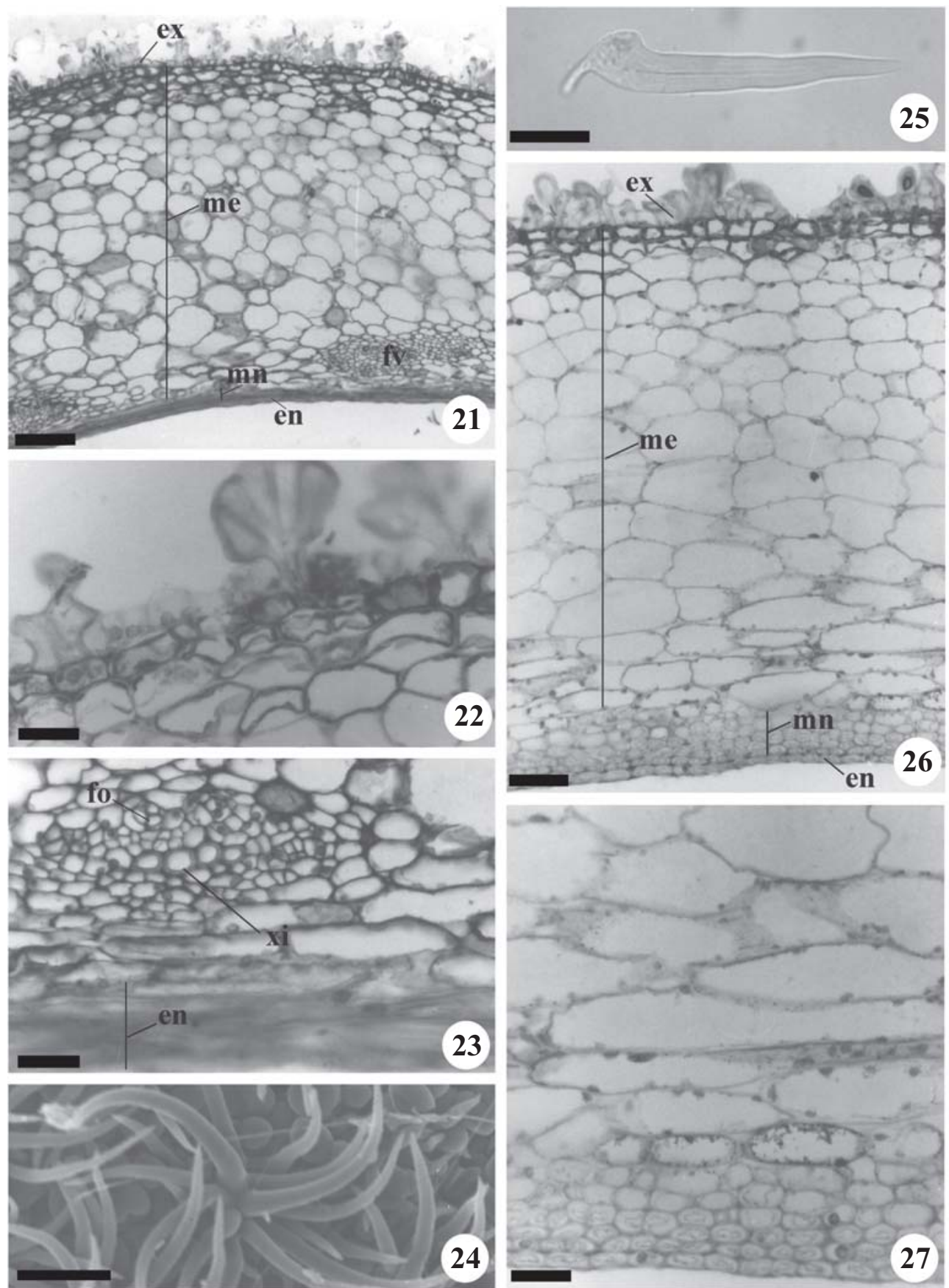

Figuras 21-27. Styrax camporum Pohl. Estádio III. Estrutura do pericarpo. Secções transversais (21-23) e longitudinais (26-27). 21. Aspecto geral do pericarpo. 22. Detalhe da figura anterior, mostrando o exocarpo com tricomas. 23. Detalhe do endocarpo e da região interna do mesocarpo, destacando um feixe colateral. 24. Aspecto do exocarpo, visto em MEV. 25. Detalhe de uma célula isolada do tricoma estrelado. 26. Aspecto geral do pericarpo. 27. Detalhe da região interna do mesocarpo e endocarpo. (en = endocarpo; $\mathrm{ex}=$ exocarpo; fo = floema; $\mathrm{fv}=$ feixe vascular; $\mathrm{me}=$ mesocarpo externo; $\mathrm{mi}=$ mesocarpo interno; $\mathrm{xi}=\mathrm{xilema})$. Barras $=100 \mu \mathrm{m}(21), 50 \mu \mathrm{m}(24,26), 25 \mu \mathrm{m}(22-23,25,27)$.

Figures 21-27. Styrax camporum Pohl. Stage III. Structure of the pericarp. Transverse sections (21-23) and longitudinal sections (26-27). 21. General aspect of the pericarp. 22. Detail of the previous figure, showing the exocarp with trichomes. 23. Detail of the endocarp and inner region of the mesocarp, detaching a collateral bundle. 24. Aspect of the exocarp, seen in SEM. 25. Detail of an isolated cell of stellate trichome. 26. General aspect of the pericarp. 27. Detail of the inner region of mesocarp and endocarp. $(\mathrm{en}=$ endocarp; $\mathrm{ex}=$ exocarp; fo = phloem; $\mathrm{fv}=$ vascular bundle; $\mathrm{me}=$ outer mesocarp; $\mathrm{mn}=\mathrm{inner} \mathrm{mesocarp}$; $\mathrm{xi}=$ xylem). Bars $=100 \mu \mathrm{m}(21), 50 \mu \mathrm{m}(24,26), 25 \mu \mathrm{m}(22-23,25,27)$. 


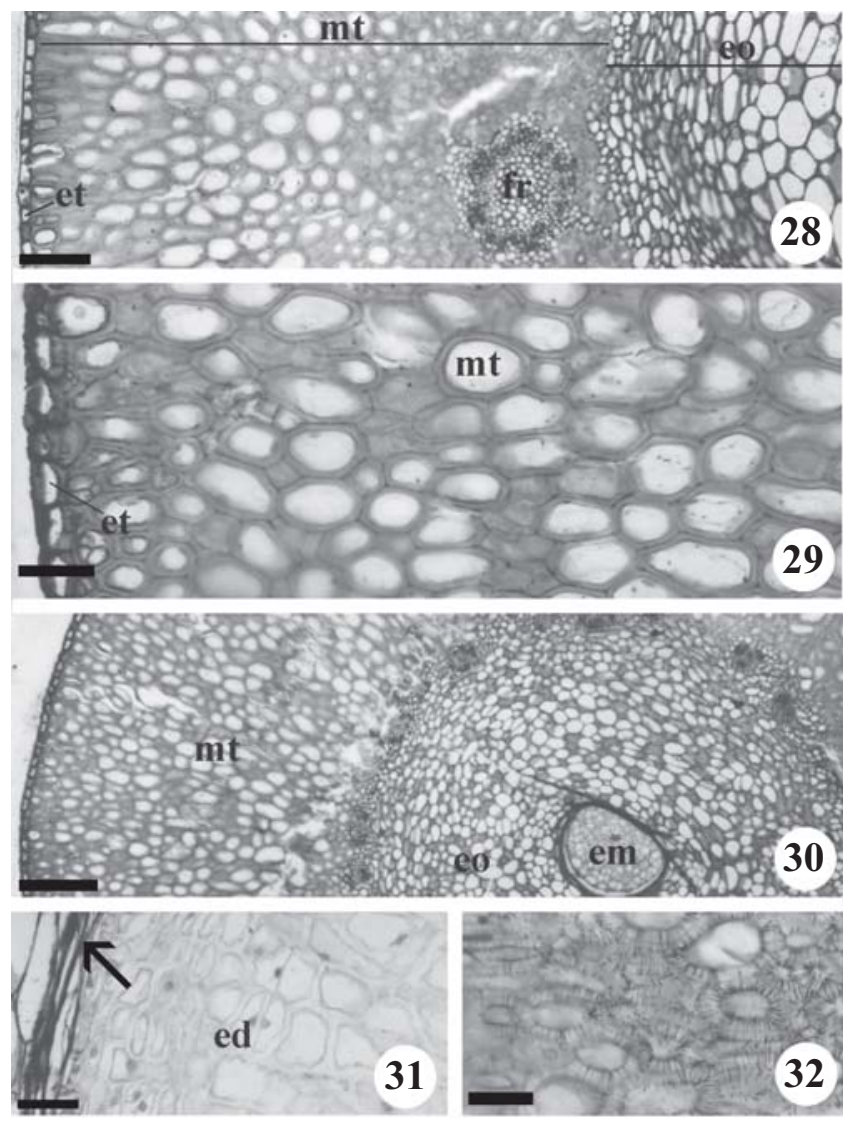

Figuras 28-32. Styrax camporum Pohl. Estádio III. Estrutura da semente. Secções transversais. 28-31. Início do estádio. 28. Aspecto geral da testa. 29. Detalhe da região externa da figura anterior. 30. Região basal da semente, mostrando a testa e o embrião. 31. Aspecto do endosperma (seta = resíduo do tégmen). 32. Esclereídes da mesotesta, ao final do Estádio III. (ed = endosperma; em = embrião; eo = mesotesta interna; et $=$ exotesta; $\mathrm{fr}=$ feixe rafeal; $\mathrm{mt}=$ mesotesta externa). Barras $=50 \mu \mathrm{m}(28,30-31), 25 \mu \mathrm{m}(29), 10 \mu \mathrm{m}(32)$.

Figures 28-32. Styrax camporum Pohl. Stage III. Structure of the seed. Transverse sections. 28-31. Beginning of the stage. 28. General aspect of the testa. 29. Detail of the outer region of the previous figure. 30. Basal region of the seed, showing the testa and the embryo. 31. Aspect of the endosperm (arrow $=$ tegmen residue). 32. Sclereids of the mesotesta at the end of Stage III. (ed = endosperm; em = embryo; eo = inner mesotesta; et $=$ exotesta; $\mathrm{fr}=$ rapheal bundle; $\mathrm{mt}=$ outer mesotesta). Bar $=50 \mu \mathrm{m}(28,30-31), 25 \mu \mathrm{m}(29), 10 \mu \mathrm{m}$ (32).

Além dos tricomas estrelados, são peculiares na epiderme externa do ovário as células comuns de formato abaulado. Dickison (1993) descreveu estas células, denominando-as de células em forma de cúpula. Com o aumento do tamanho do fruto, pode-se verificar o alongamento tangencial destas células, que têm seu formato modificado.
Dickison (1993) descreveu a ocorrência de tricomas intra-ovarianos em vários gêneros de Styracaceae, porém destacou que, no gênero Styrax, os tricomas intra-ovarianos não foram encontrados. O presente trabalho corrobora as observações do autor.

A vascularização observada nos ovários é típica, destacando-se a ocorrência de fusão filogenética dos feixes ventrais de cada carpelo. Também é interessante destacar que os feixes ventrais, relacionados à irrigação dos óvulos, não são observados no ápice do ovário, onde ele é unilocular e a placenta não se desenvolve. Esta característica foi constatada também em S. suberifolius Hook. \& Arn. (Dickison 1993).

Com relação ao mesofilo ovariano, observam-se muitas drusas e idioblastos fenólicos. Dickison (1993) afirmou que esta característica é comum a todas as espécies de Styrax por ele examinadas, inclusive $S$. camporum.

Correspondendo à descrição feita por Corner (1976) para as Styracaceae, os óvulos de S. camporum são bitegumentados e tenuinucelados. Os dois tegumentos do óvulo são bastante unidos, porém, numa observação acurada, é possível diferenciá-los. No entanto, Dickison (1993) afirmou que, no gênero Styrax, os tegumentos são distintos somente na extremidade micropilar de cada óvulo, dado não corroborado pelas observações em $S$. camporum.

$\mathrm{Na}$ espécie estudada, é possível reconhecer a presença do endotélio, camada mais interna e diferenciada do tegumento interno do óvulo. Segundo Werker (1997), o endotélio é normalmente unisseriado, contém citoplasma denso e circunda completamente o gametofito feminino, sendo completamente absorvido durante a ontogênese seminal. Estas características correspondem ao observado em $S$. camporum. Segundo Von Teichman \& Van Wyk (1991), em grupos considerados mais primitivos o endotélio é ausente.

Dickison (1993) citou, ainda, a presença de grãos de amido no megagametofito em vários gêneros de Styracaceae, porém não foi constatada a presença no gênero Styrax. O autor ponderou que a ausência de amido no material observado de Styrax poderia ser devida a problemas na fixação. No presente trabalho, não foi constatada a presença de amido em nenhuma região dos óvulos de $S$. camporum, mesmo as amostras tendo sido fixadas e preparadas com o devido cuidado.

Apesar de cada ovário de S. camporum conter cerca de 20 óvulos (Saraiva et al. 1988), foi possível observar neste trabalho que apenas um óvulo é fecundado, enquanto os demais interrompem seu 


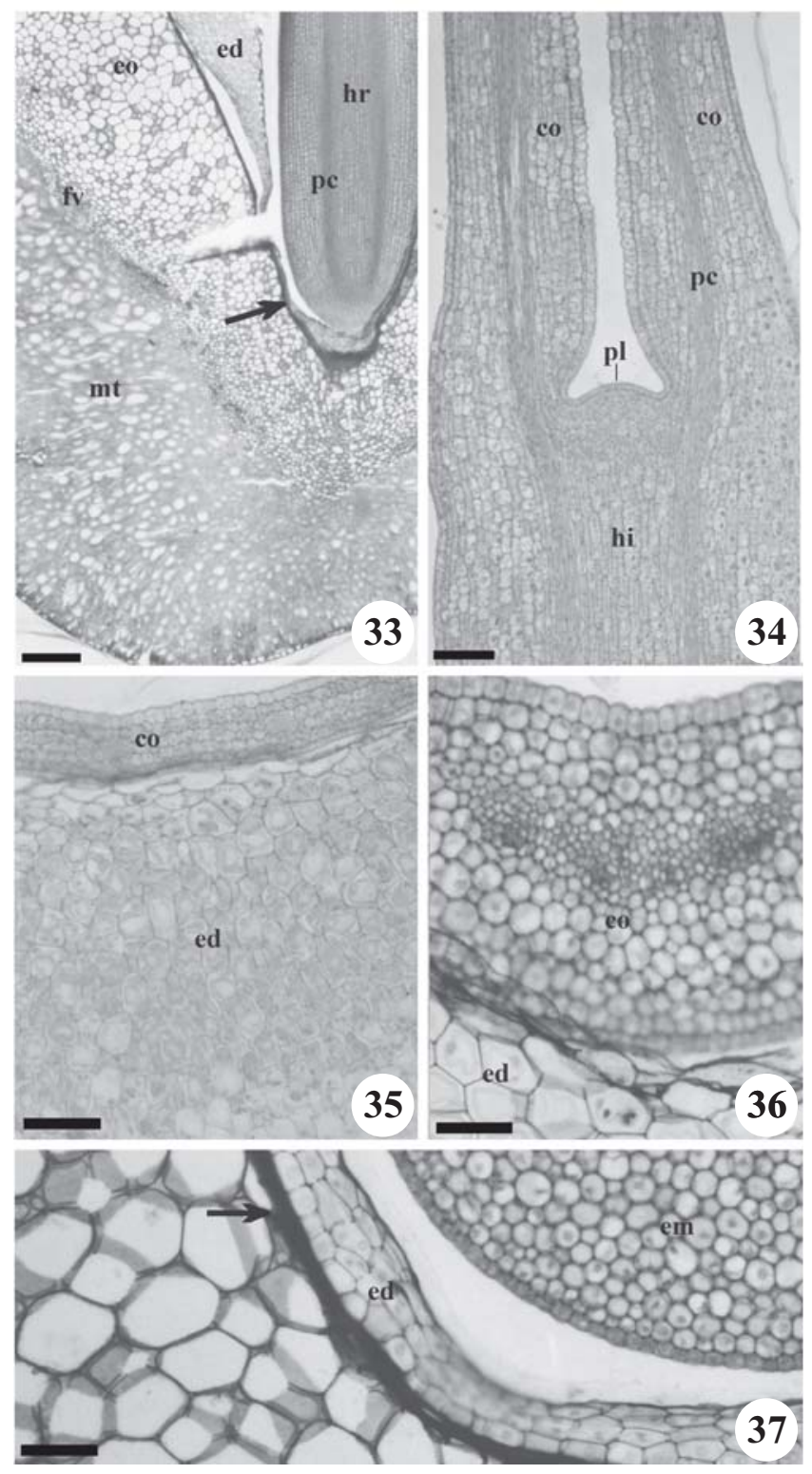

Figuras 33-37. Styrax camporum Pohl. Estádio III. Semente. Secções longitudinais (33-34) e transversais (35-37). 33. Aspecto geral mostrando a base do embrião; notar o endosperma reduzido nesta região (seta $=$ resíduo do tégmen $)$. 34. Detalhe do nó cotiledonar, mostrando a plúmula indiferenciada. 35. Aspecto geral de um cotilédone e do endosperma. 36. Detalhe da nervura central do cotilédone. 37. Detalhe da mesotesta interna, endosperma e embrião; notar células colapsadas resultantes da compressão do tégmen (seta). ( co = cotilédone; ed = endosperma; em = embrião; eo $=$ mesotesta interna $; \mathrm{fv}=$ feixe vascular; $\mathrm{hi}=$ hipocótilo; $\mathrm{hr}=$ eixo hipocótilo-radícula; $\mathrm{mt}=$ mesotesta externa; $\mathrm{pl}=$ plúmula, $\mathrm{pc}=$ procâmbio). Barras $=200 \mu \mathrm{m}(33), 100 \mu \mathrm{m}(34-35), 25 \mu \mathrm{m}$ (36-37). desenvolvimento. A formação de frutos monospérmicos a partir de ovários multiovulados, acompanhada de completa reabsorção dos óvulos não fecundados, é a tônica de muitos tipos de frutos, não somente drupas ou drupóides. Martins \& Oliveira (2001) verificaram a presença de vários óvulos aparentemente viáveis em Tipuana tipu (Benth.) O. Kuntze (Fabaceae), mas somente um deles é fecundado, originando um fruto monospérmico do tipo sâmara, segundo o processo anteriormente descrito.

Ao realizar o estudo ontogenético de frutos carnosos, principalmente drupas, é comum a divisão em períodos de crescimento (Lilleland 1930, 1932, 1933, Tukey \& Young 1939, Nitsch 1953). Esses autores reconheceram o ovário e mais três períodos distintos de crescimento: no período I, ocorre um rápido aumento no tamanho do fruto e tegumentos seminais; no período II, o embrião diferencia-se, embora o fruto diminua sua velocidade de crescimento; no período III, o embrião já está formado, porém o fruto retoma seu crescimento devido um grande alongamento celular no pericarpo. Os três períodos de crescimento descritos pelos autores acima correspondem precisamente ao processo aqui relatado para os frutos de $S$. camporum. De acordo com Roth (1977), em frutos tipo drupa (senso lato), ocorre assincronia entre o crescimento do embrião e do pericarpo, visto que ambos competem pelas mesmas reservas, advindas da planta-mãe.

A maioria dos autores classificam os frutos das espécies de Styrax como drupas. Barroso et al. (1999) descreveram o fruto como "drupa com parede pouco carnosa, de cerca de 0,5 a 1,0 cm de comprimento". Outros autores também consideraram os frutos das Styracaceae como drupa (Aranha 1968, Spjut 1994) ou drupóides (Perkins 1907).

Roth (1977) classificou as drupas como um tipo de fruto altamente desenvolvido, dividido em duas partes

Figures 33-37. Styrax camporum Pohl. Stage III. Seed. Longitudinal sections (33-34) and transverse sections (35-37). 33. General aspect showing the base of the embryo; note the reduced endosperm in this region ( arrow $=$ tegmen residue). 34. Detail of the cotyledonal node, showing indifferenciated plumule. 35. General aspect of one cotyledon and endosperm. 36. Detail of the cotyledon midrib. 37. Detail of the inner mesotesta, endosperm and embryo; to note collapsed cells resultant of the tegmen compression (arrow). (co = cotyledon; ed = endosperm; em = embryo; eo = inner mesotesta; $\mathrm{fv}=$ vascular bundle; $\mathrm{hi}=$ hypocotyl $\mathrm{hr}=$ embryo axis; $\mathrm{mt}=$ outer mesotesta; $\mathrm{pl}=$ plumule; $\mathrm{pc}=$ procambium $).$ Bars $=200 \mu \mathrm{m}(33)$, $100 \mu \mathrm{m}(34-35), 25 \mu \mathrm{m}(36-37)$. 


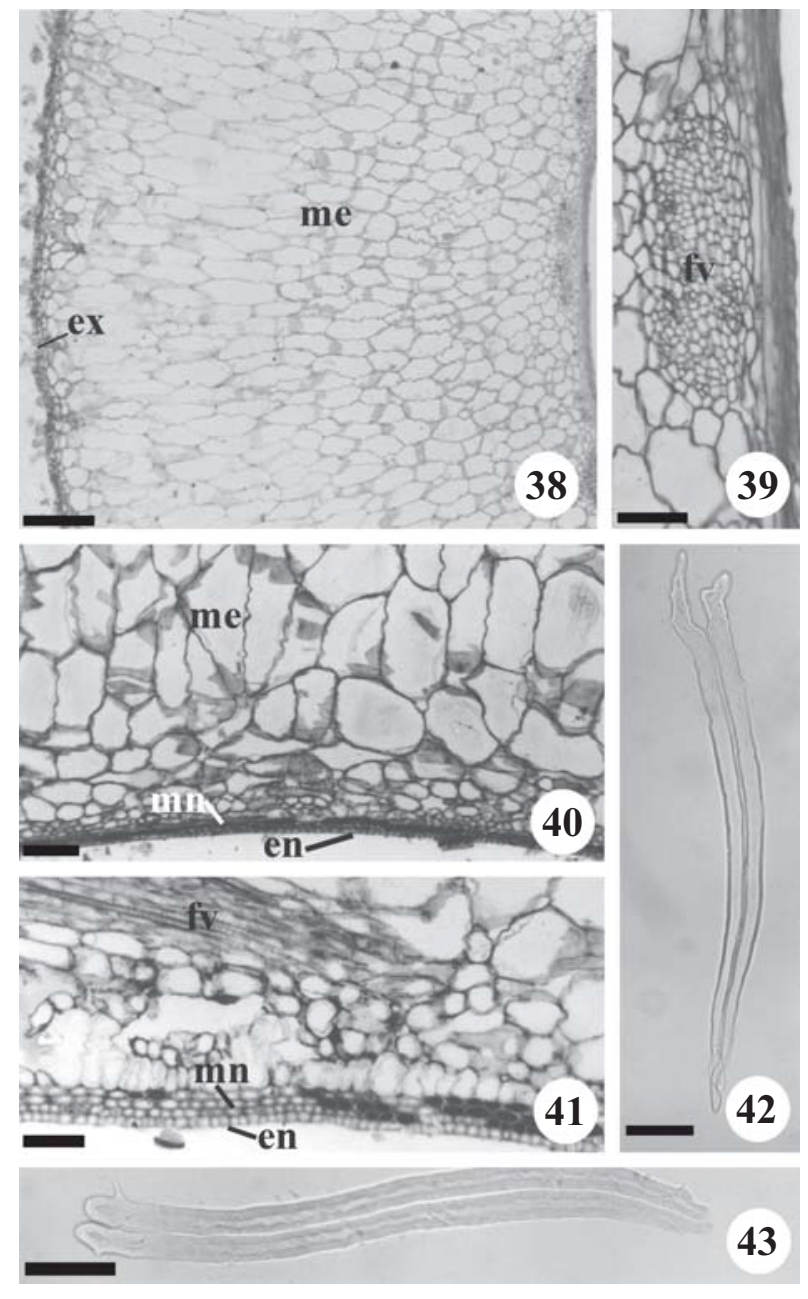

Figuras 38-43. Styrax camporum Pohl. Estádio IV. Estrutura do pericarpo maduro. Secções transversais (38-39) e longitudinais (40-41). 38. Aspecto geral do pericarpo. 39. Detalhe do pericarpo, destacando um feixe vascular e o endocarpo. 40-41. Mesocarpo e endocarpo. 42-43. Fibras dissociadas do endocarpo. $(\mathrm{en}=$ endocarpo; $\mathrm{ex}=$ exocarpo; $\mathrm{fv}=$ feixe vascular; $\mathrm{me}=$ mesocarpo externo; $\mathrm{mn}=$ mesocarpo interno $)$. Barras $=$ $200 \mu \mathrm{m}(38), 100 \mu \mathrm{m}(40), 50 \mu \mathrm{m}(39,41,42), 25 \mu \mathrm{m}(43)$.

Figures 38-43. Styrax camporum Pohl. Stage IV. Structure of the mature pericarp. Transverse sections (38-39) and longitudinal sections (40-41). 38. General aspect of the pericarp. 39. Detail of the pericarp, detaching a vascular bundle and the endocarp. 40-41. Mesocarp and endocarp. 42-43. Endocarp dissociated fibers. (en = endocarp; ex = exocarp; $\mathrm{fv}=$ vascular bundle; $\mathrm{me}=$ outer mesocarp; $\mathrm{mn}=$ inner mesocarp). Bars $=200 \mu \mathrm{m}(38), 100 \mu \mathrm{m}(40), 50 \mu \mathrm{m}$ (39, 41, 42), $25 \mu \mathrm{m}(43)$.

muito especializadas, sendo o mesocarpo carnoso, freqüentemente comestível, atrativo para a dispersão, e um endocarpo duro, que protege a semente. Segundo
Ferri et al. (1981), drupa é um fruto simples, carnoso, com endocarpo lenhoso e concrescido com o tegumento da única semente geralmente existente, formando o que se costuma chamar de "caroço" (pirênio), que representa a unidade de dispersão. Spjut (1994) descreveu drupa como fruto que apresenta pericarpo carnoso com um ou mais pirênios, sendo o pirênio uma "concha" que abrange uma ou mais sementes. De acordo com Vidal \& Vidal (1999), drupa é um fruto monocárpico, monospérmico, de endocarpo endurecido, concrescente com a semente formando o "caroço" (pirênio). Paralelamente, Barroso et al. (1999) definiram drupa como sendo o fruto produzido por dois ou mais carpelos (raramente um só), de formas variadas mas freqüentemente globoso, elipsóide ou piriforme, com endocarpo (pirênio) único, com espaço central amplo, não dividido em lóculos, apresentando uma ou duas sementes. Segundo as autoras, classificam-se como drupóides os frutos cujos pirênios formam dois ou mais lóculos.

Durigan et al. (2004) descreveram o fruto de $S$. camporum como drupa ovóide pubescente, com cálice persistente. Machado (1991) classificou o fruto de S. camporum como drupáceo. É possível afirmar que o fato que motivou estes autores a classificarem os frutos de $S$. camporum como drupa ou drupáceo foi a presença da região lignificada, justaposta ao pericarpo, que simula a estrutura do pirênio, apesar deste estudo ontogenético não deixar dúvidas sobre sua origem tegumentar. Vale destacar que o mesocarpo interno e endocarpo também são constituídos por células lignificadas, mas que possuem consistência papirácea em função do pequeno número de camadas celulares. Este tipo de estrutura foge à definição clássica de drupa (Roth 1977, Ferri et al. 1981, Spjut 1994, Barroso et al. 1999, Vidal \& Vidal 1999), de modo que os frutos de S. camporum devem ser classificados como bagas, como proposto por Ferri (1969), já que a proteção da semente é dada pelo tegumento e não pelo endocarpo.

É interessante destacar que os frutos de $S$. camporum apresentam cálice persistente, característica esta descrita como típica das Styracaceae (Perkins 1907, Ferri 1969).

Quanto ao número de sementes formadas, apesar de alguns autores afirmarem que $S$. camporum pode apresentar até duas ou três sementes (Aranha 1968, Machado 1991), neste trabalho foi encontrada apenas uma semente por fruto.

Anatomicamente, verificou-se que o pericarpo maduro de $S$. camporum apresenta uma camada de 
células colenquimatosas. Roth (1977) afirmou que, nas drupas, pode ocorrer uma hipoderme colenquimatosa, apresentando células de paredes espessas e alongadas tangencialmente, tal qual a região externa do mesocarpo aqui descrito. Ainda com relação ao mesocarpo, merece destaque que os idioblastos cristalíferos e fenólicos mantêm-se desde o ovário até a estrutura madura. Tal aspecto pode ser reconhecido como adaptação ao bioma cerrado, ambiente em que existe grande predação de frutos e sementes e onde tais estruturas ocorrem freqüentemente.

A estrutura da semente de $S$. camporum corresponde à descrição das características gerais das Styracaceae feita por Corner (1976), destacando-se que as sementes apresentam testa espessa e são albuminosas.

Um aspecto que chama a atenção é a mesotesta externa das sementes de $S$. camporum, composta por espessa camada de braquiesclereídes. Segundo Werker (1997), esclereídes são comuns nos tegumentos, variando com relação à espessura da parede, podendo constituir camadas ou agrupamentos entre células de outra natureza. A formação de camada espessa de células lignificadas confere grande resistência mecânica ao tegumento de S. camporum, cuja semente pode ser enquadrada como mesotestal segundo a classificação proposta por Corner (1976).

É possível verificar que, na exotesta, todas as células são fenólicas. Segundo Swain (1979), os compostos fenólicos são encontrados em todas as classes de plantas vasculares e atuam na defesa de tecidos vegetais contra herbívoros. Werker (1997) reforçou esta afirmativa e indicou que os compostos fenólicos nas sementes aparentemente atuam na proteção contra herbívoros, fungos e bactérias, tendo ainda possível efeito contra vírus; também ajudam a tornar os tegumentos mais duros e impermeáveis; funcionam como inibidores da germinação e conferem a coloração amarronzada a muitas sementes.

É também digna de nota a grande quantidade de reserva lipídica na mesotesta externa das sementes maduras analisadas, quando o embrião já se encontra completamente diferenciado. O papel nutritivo dos tegumentos é conhecido e referido especialmente durante o desenvolvimento da semente, quando os envoltórios podem participar da transferência de materiais de reserva para o endosperma $\mathrm{e}$, em última instância, para o embrião, durante o processo de embriogênese. Segundo Werker (1997), mais raramente, substâncias nutritivas podem ser encontradas nos tegumentos maduros, constituindo reservas que serão consumidas durante a germinação, o que é o caso de $S$. camporum.

A observação de resíduos do tégmen compondo uma camada de paredes comprimidas como visto nas sementes de $S$. camporum é freqüentemente registrada.
De acordo com Werker (1997), é comum a formação de camadas de células comprimidas tanto externamente na semente, quanto internamente, neste caso resultando da compressão de várias camadas celulares, algumas vezes de todo o tegumento interno, conferindo proteção ao embrião.

Com relação ao endosperma, as sementes da espécie estudada apresentam o padrão da família citado por Corner (1976), sendo formado de modo celular e mantido em grande quantidade na semente, acumulando lipídios.

O embrião de $S$. camporum é reto, conferindo com as descrições feitas por vários autores (Perkins 1907, Aranha 1968, Corner 1976). Segundo as classificações de Martin (1946) e de Barroso et al. (1999), este embrião é axial e contínuo, do tipo espatulado.

Agradecimentos - À Fapesp (processo BIOTA n ${ }^{\circ} 00 / 12469-3$ ), pelo apoio financeiro, e à Capes, pela bolsa de mestrado de P.G.S. Julio.

\section{Referências bibliográficas}

ARANHA, C. 1968. Styracaceae do Estado da Guanabara. Atas da Sociedade de Biologia do Rio de Janeiro 12:47-52.

BARROSO, G.M., MORIM, M.P., PEIXOTO, A.L. \& ICHASO, C.L.F. 1999. Frutos e sementes: morfologia aplicada à sistemática de dicotiledôneas. Editora UFV, Viçosa.

CORNER, E.J.H. 1976. The seeds of dicotyledons. University Press, Cambridge.

DICKISON, W.C. 1993. Floral anatomy of the Styracaceae, including observations on intra-ovarian trichomes. Botanical Journal of the Linnean Society 112:223255.

DURIGAN, G., BAITELLO, J.B., FRANCO, G.A.D.C. \& SIQUEIRA, M.F. 2004. Plantas do cerrado paulista: imagens de uma paisagem ameaçada. Páginas e Letras Editora e Gráfica, São Paulo.

FAHN, A. 1986. Structural and functional properties of trichomes of xeromorphic leaves. Annals of Botany 57:631-637.

FERRI, M.G.1969. Plantas do Brasil:espécies do cerrado. Edgard Blücher, São Paulo.

FERRI, M.G., MENEZES, N.L. \& MONTEIRO, W.R. 1981. Glossário ilustrado de Botânica. Nobel, São Paulo.

GERLACH, G. 1969. Botanische Mikrotehnik, eine Einfuhrung. George Thieme, Stuttgart.

HUTCHINSON, J. 1973. The families of flowering plants. $3^{\text {rd }}$ ed. Clarendon Press, Oxford.

JOHANSEN, D.A. 1940. Plant microtechnique. McGraw-Hill Book, New York.

JUDD, W.S., CAMPBELL, C.S., KELLOGG, E.A. \& STEVENS, P.F. 1999. Plant systematics: a phylogenetic approach. Sinauer Associates, Sunderland. 
KARNOVSKY, M.J. 1965. A formaldehyde-glutaraldehyde fixative of high osmolality for use in electron microscopy. Journal of Cell Biology 27:137A-138A.

KRAUS, J.E. \& ARDUIN, M. 1997. Manual básico de métodos em Morfologia Vegetal. EDUR, Seropédica.

LILLELAND, O. 1930. Growth study of the apricot fruit. Proceeding of the American Society for Horticultural Science 27:237-245.

LILLELAND, O. 1932. Growth study of the peach fruit. Proceeding of the American Society for Horticultural Science 29:8-12.

LILLELAND, O. 1933. Growth study of the plum fruit - I. The growth and changes in chemical composition of the climax plum. Proceeding of the American Society for Horticultural Science 30:203-208.

LORENZI, H. 1992. Árvores brasileiras: manual de cultivo e identificação de plantas arbóreas nativas do Brasil. Plantarum, Nova Odessa.

MACHADO, S.R. 1991. Morfologia e anatomia dos órgãos vegetativos de Styrax camporum Pohl. (Styracaceae) em desenvolvimento. Tese de doutorado, Universidade de São Paulo, São Paulo.

MARTIN, A.C. 1946. The comparative internal morphology of seeds. American Midland Naturalist 36:513-660.

MARTINS, M.A.G. \& OLIVEIRA, D.M.T. 2001. Morfoanatomia e ontogênese do fruto e semente de Tipuana tipu (Benth.) O. Kuntze (Fabaceae: Faboideae). Revista Brasileira de Botânica 24:109-121.

MENDONÇA, R.C., FELFILI, J.M., WALTER, B.M.T., SILVA JÚNIOR, M.C., REZENDE, A.V., FILGUEIRAS, T.S. \& NOGUEIRA, P.E. 1998. Flora vascular do cerrado. In Cerrado: ambiente e flora (S.M. Sano \& S.P. Almeida, eds.). Embrapa - CPAC, Brasília, p.288-556.

MORS, W.B. \& RIZZINI, C.T. 1966. Useful plants of Brazil. Holdeu-Day, Amsterdam.

NAKAJIMA, J.N. \& MONTEIRO, R. 1986. Estudos fitogeográficos com espécies de Styrax L. (Styracaceae) dos cerrados brasileiros. Eugeniana 12:3-10.
NITSCH, J.P. 1953. The physiology of fruit growth. Annual Review of Plant Physiology 4:199-236.

O'BRIEN, T.P., FEDER, N. \& MCCULLY, M.E. 1964. Polychromatic staining of plant cell walls by toluidine blue O. Protoplasma 59: 367-373.

PERKINS, J. 1907. Styracaceae. Das Pflanzenreich IV 241:1-111.

ROBARDS, A.W. 1978. An introduction to techniques for scanning electron microscopy of plant cells. In Electron microscopy and cytochemistry of plant cells (J.L. Hall, ed.). Elsevier, New York.

RODRIGUES, V.E.G. \& CARVALHO, D.A. 2001. Plantas medicinais no domínio dos cerrados. UFLA, Lavras.

ROTH, I. 1977. Fruits of Angiosperms. Gebrüder Borntraeger, Berlin.

SARAIVA, L.C., CESAR, O. \& MONTEIRO, R. 1988. Biologia da polinização e sistema de reprodução de Styrax camporum Pohl. e S. ferrugineus Nees et Mart. (Styracaceae). Revista Brasileira de Botânica 11:71-80.

SASS, J.E. 1951. Botanical microtechnique. $3^{\text {rd }}$ ed. Iowa State University Press, Ames.

SPJUT, R.W. 1994. A systematic treatment of fruit types. Memoirs of the New York Botanical Garden 70:1-182.

SWAIN, T. 1979. Tannins and lignins. In Herbivores: their interactions with secondary plant metabolites (G.A. Rosenthal \& D.H. Janzen, eds.). Academic Press, New York, p.657-682.

TUKEY, H.B. \& YOUNG, J.O. 1939. Histological study of the developing fruit of the sour cherry. Botanical Gazette 100:723-749.

VIDAL, W.N. \& VIDAL, M.R.R. 1999. Botânica: organografia. $3^{\mathrm{a}}$ ed. Editora UFV, Viçosa.

VON TEICHMAN, I. \& VAN WYK, A.E. 1991. Trends in the evolution of dicotyledonous seeds based on character associations, with special reference to pachychalazy and recalcitrance. Botanical Journal of the Linnean Society 105:211-237.

WERKER, E. 1997. Seed anatomy. Gebrüder Borntraeger, Berlin. 